\title{
Optimization of the Spreadable Modified Butter Manufacturing by Response Surface Methodology
}

\author{
Mun Hui Suh, Keon Bong Lee, and Seung Chun Baick* \\ Institute of Dairy Food Research, Seoul Dairy Co-operative, Ansan 425-838, Korea
}

\begin{abstract}
The aim of this study was to optimize the manufacturing condition of spreadable modified butter by RSM. Based on the central composite design, the degree of optimization was expressed as a SFC as a dependent variable (Y, \%) determined by NMR with 23 experimental groups. Three independent variables were the contents of butter $\left(\mathrm{X}_{1}, 35-75 \%\right)$, the contents of grape seed oil $\left(\mathrm{X}_{2}, 15-35 \%\right)$, and the contents of hydrogenated soybean oil $\left(\mathrm{X}_{3}, 0-4 \%\right)$. As the result, $\mathrm{SFC}$ at $10^{\circ} \mathrm{C}$ was ranged from 32.37 to $42.76 \%$. In addition, the regression coefficients were calculated for SFC at $10^{\circ} \mathrm{C}$ by RSREG. The regression model equation for the SFC was $\mathrm{Y}=39.18-0.04 \mathrm{X}_{1} \mathrm{X}_{3}$. Consequently, the optimal contents for manufacturing spreadable modified butter were determined as $55.18 \%$ for butter, $40.78 \%$ for grape seed oil, and $4.08 \%$ for hydrogenated soybean oil, respectively. The predicted response value for SFC at $10^{\circ} \mathrm{C}$ was $30.20 \%$, comparable to the actual experimental SFC value as $29.85 \%$. Finally hardness and spreadability in reference butter and spreadable modified butter produced under the optimal conditions was measured. The hardness in spreadable modified butter was $31.80 \mathrm{~N}$ as compared to $69.92 \mathrm{~N}$ in reference butter. The spreadability in spreadable modified butter was 5.6 point as compared to reference butter. This difference may be due to the contents of solid fat by butter and hydrogenated soybean oil. This study showed that the SFC value at $10^{\circ} \mathrm{C}$ could be a suitable indicator for the manufacturing spreadable modified butter to predict important attributes such as mouth feel, hardness and spreadability.
\end{abstract}

Key words: spreadable modified butter, response surface methodology, solid fat content, nuclear magnetic resonance, hardness, spreadability

\section{Introduction}

Butter notoriously possesses poor spreadability at refrigeration temperatures, and poor structural stability at room temperatures (Kaylegian and Lindsay, 1992). At room temperature, butter also demonstrates oiling off and moisture migration (DeMan and Wood, 1958; Shukla et al., 1994). Texture is one of the 4 quality factors determining butter's acceptability (Bourne, 1982). It influences spreadability, taste, mouth feel, appearance, and butter's suitability for various uses (Mulder and Walstra, 1974). This has been an area of great interest and economical importance for dairy industries around the world, with the primary focus being improved butter spreadability (Kawanari et al., 1981). Therefore, the texture of butter is important considerations in quality evaluations.

\footnotetext{
*Corresponding author: Seung Chun Baick, Institute of Dairy Food Research, Seoul Dairy Cooperative, Ansan 425-838, Korea. Tel: 8231-491-3867, Fax: 82-31-491-9179, E-mail: baicksc@seoulmilk. co.kr
}

Spreadability and hardness as texture related properties represent important aspects in consumer acceptability of solid edible fats, such as butter and margarine (Frede and Precht, 1988). Solid fat content (SFC) strongly influences the mechanical behavior of fats, although relying on SFC alone to predict hardness has been shown to be unreliable (Narine and Marangoni, 1999a, 1999b). In the food industry, SFC values measured at different temperatures can be used to help predict important attributes such as mouth-feel and hardness.

Response surface methodology (RSM) is a useful tool for optimizing the quality of foods. Following appropriate statistical designs, the experimental data relate the variation in the dependent variables to variations in the independent variables (Damasio et al., 1999; Gacula, 1993). An optimal formulation maximizes consumer acceptance in that it is the best possible formulation given a fixed set of ingredients (Acosta and Cubero, 2008; Damasio et al., 1999; Gan et al., 2006). RSM was successfully used to identify the best combination of ingredients in newly developed products with health-promoting characteristics, 
such as soy-based desserts (Granato et al., 2010a; Granato et al., 2010b).

Taking the above into consideration and with optimizing the $\mathrm{SFC}$ at $10^{\circ} \mathrm{C}$ (refrigeration temperatures) of a spreadable modified butter, this work studies the effect of butter content, grape seed oil content, and hydrogenated soy bean oil content on the spreadability and hardness of spreadable modified butter. The aim of this study was to establish the optimal manufacturing spreadable modified butter by means of RSM. The effectiveness of optimal spreadable modified butter was evaluated as a SFC at $10^{\circ} \mathrm{C}$ of butter.

The optimization of the spreadable modified butter as content of solid fat by response surface methodology was investigated. And the rheological properties of spread butter as content of solid fat were examined. In this study, optimization of the spreadable modified butter and rheological properties correlated with hardness and spreadability were investigated.

\section{Material and Methods}

\section{Materials}

Because of their competitive price in market, soybean and partially hydrogenated soybean oil are commonly used industrially. However, soybean oil is higher content of saturated fatty acids than grape seed oil (Table 1) which is predicted to be good for the spreadability of the products. This study was prepared for lipid system composed of grape seed oil and hydrogenated soybean oil. Blends of grape seed oil and hydrogenated soybean oil were supplied by Lottesamkang (Lottesamkang, Korea).

\section{Butter blends processing}

The oil phase was prepared by mixing butter (Seoul dairy co-op., Korea), grape seed oil and hydrogenated soybean oil at $60^{\circ} \mathrm{C}$. The aqueous phase was prepared by water. The butter blends were processed by first preparing an oil phase by stirring in a beaker. The aqueous phase $\left(45^{\circ} \mathrm{C}\right)$ was added continuously to the oil phase $\left(60^{\circ} \mathrm{C}\right)$ with stirring. The scraped blades remove crystallizing fat from the cold walls and so maintain the heat transfer characteristics of the unit while promoting nucleation of crystallization. The spreadable modified butters were stored at $5^{\circ} \mathrm{C}$ for post-crystallization.

\section{NMR measurements}

The solid fat content (SFC, \%) of spreadable modified butters was analyzed by nuclear magnetic resonance (NMR). The SFC was obtained from pNMR (Bruker minispec 20i spectrometer, Germany). The melted spread butter were introduced into glass NMR tubes, placed in a thermostatic water bath and cooled from 50 to $5^{\circ} \mathrm{C}$ at an average rate of $1^{\circ} \mathrm{C} / \mathrm{min}$. SFC was monitored as the temperature changed from 50 to $5^{\circ} \mathrm{C}$ upon cooling. The tubes were left to equilibrate overnight at $5^{\circ} \mathrm{C}$, and changes in SFC were monitored from 5 to $50^{\circ} \mathrm{C}$ upon heating at a rate of $1^{\circ} \mathrm{C} / \mathrm{min}$ as well (Singh et al., 2004).

\section{Experimental designs for Response Surface by least-square regression (RSREG)}

Central composite design designed the process optimization of the manufacturing of spreadable modified butter. RSM was applied to optimize the manufacturing of spreadable modified butter by means of three independent variables; the content of butter $\left(\mathrm{X}_{1}\right)$, ranging from 35 to $75 \%$, the content of grape seed oil $\left(\mathrm{X}_{2}\right)$, from 15 to $35 \%$, and the hydrogenated soybean oil $\left(\mathrm{X}_{3}\right)$ from 0 to $4 \%$.

The optimization conditions were studied at the central of the design to find the accurate results of statistical experimentation. At the beginning of the studies, the second-order composite design, with fractional $2^{4}$ factorial points ( 16 points), star points (6 points) and central point (1 point), was effective in searching for the direction of the optimum domain.

The regression model equation for the SFC of spreadable modified butter could be predicted as follows.

$$
Y=b_{0}+\sum_{i=1}^{3} b i X i+\sum_{i=1}^{3}(b i i X i)^{2}+\sum_{i=1 j=i+1}^{23} b i j X i X j
$$

where, Y (\%) was the SFC of spreadable modified butter;

Table 1. Free fatty acid content of samples

\begin{tabular}{|c|c|c|c|c|c|c|c|c|c|}
\hline \multirow{2}{*}{ Sample } & \multicolumn{9}{|c|}{ Free fatty acids content $(\%)$} \\
\hline & $\mathrm{C}_{8}$ & $\mathrm{C}_{10}$ & $\mathrm{C}_{12}$ & $\mathrm{C}_{14}$ & $\mathrm{C}_{16}$ & $\mathrm{C}_{16-1}$ & $\mathrm{C}_{18}$ & $\mathrm{C}_{18-1}$ & $\mathrm{C}_{18-2}$ \\
\hline Butter & 2.0 & 5.2 & 8.0 & 19.0 & 38.1 & 2.1 & 8.8 & 14.4 & 1.4 \\
\hline Grape seed oil & & & & & 9.0 & & 3.2 & 14.8 & 73.0 \\
\hline Hydrogenated soybean oil & & & 0.4 & 0.4 & 13.8 & & 18.3 & 66.7 & 0.5 \\
\hline Soy bean oil & & & & & 13.3 & & 3.3 & 24.0 & 55.1 \\
\hline
\end{tabular}


subscripts $i$ and $j$ took values from 1 to the number of variables $(n)$; the $b_{\mathrm{o}}$ was the intercept term; the $b_{i}$ values were linear coefficient; the $b_{i j}$ values were quadratic coefficient; $X_{i}$ and $X_{j}$ were the level of the independent variables. The analysis of data was carried out using Statistical Analysis System (SAS) program (SAS, 2003).

\section{The rheological properties on spreadable modified butter: Hardness measurement}

Hardness measurements were observed under a Texture analysis system TA-plus (AMETEK Lloyd Instruments Ltd., UK). The most commonly used test to evaluate spreadable modified butter texture has been penetrometer (DeMan and Beers, 1987). One convenient method is cone penetrometer. In this method a cone suspended on a shaft is released from a starting position with its tip on the surface of the sample It is difficult that tip was mounted above the surface of the spreadable modified butter with the come tip just touching the clean surface. Thus, a study was used test to determinate texture has been cutting penetrometer. Cutting test has also been used to derive a yield stress for spreadable modified butter. Hardness was determined by petri dish ( 4 inch diameter) and $10 \mathrm{~mm}$ in height. Using a wire $25 \mathrm{~mm}$ cutting penetrometer was applied to penetration depth $10 \mathrm{~mm}$, and it moved downward at a rate of $50 \mathrm{~mm} / \mathrm{min}$. The force of downward stress was recorded an $\mathrm{N}$.

\section{Sensory evaluation: Spreadability}

The reference butter and spreadable modified butter manufacturing under the optimal conditions were compared with spreadability test. A ten member's panel of 6 females and 4 male were evaluated texture properties. The $10^{\circ} \mathrm{C}$ butter sample with a given magnitude of 10 served as standard stimulus for the basic experiment. The reference sample, conditioned at $10^{\circ} \mathrm{C}$, served as reference in the comparative study. Evaluation was repeated twice. Spreadability was determined by spreading cylindrical specimens $14 \mathrm{~mm}$ in diameter and $10 \mathrm{~mm}$ in height with a knife on filter paper. The 7-point hedonic scale was used to compare the degreed of liking of two samples.

\section{Statistical analysis}

A randomized complete block design with 44 factorial arrangements was used. Replication $(n=3)$ was blocked and the additive treatment and the incubation time were the main treatment factors. The general linear model (GLM) procedure was applied to the data with a level of $p<0.05$ for statistical analysis (SAS, 2003) and least significance difference (LSD) were used to compare the mean differences among treatment samples.

\section{Results and Discussion}

\section{Optimization of manufacturing of spreadable mod- ified butter by response surface methodology}

Based on the central composite design, the SFC of each experimental group (total 23 data points, $n=3$ ) was determined and the obtained data were analyzed by SAS. The SFC at $10^{\circ} \mathrm{C}$ of spreadable modified butter was in the range from 32.37 to $42.76 \%$ (Table 3 ). The results on the regression coefficients calculated for the degree of SFC of butter by RSREG were shown in Table 4 . The linear regression was significant at the level of $p<0.01$, but quadratic regression $(p>0.05)$ and cross product regression $(p>0.30)$ were not significant. As for the spreadable modified butter, the regression model equation for the SFC (Y, $\%$ ) to the change of an independent variable could be predicted as follow: $\mathrm{Y}=39.18-0.04 \mathrm{X}_{1} \mathrm{X}_{3}$. According to the model equation, the content of butter $\left(\mathrm{X}_{1}\right)$ and hydrogenated soybean oil $\left(\mathrm{X}_{3}\right)$ were believed to be the major factors affect the SFC among the variables studied. The grape seed oil was shown to have little effect on the SFC of spreadable modified butter. This revealed that the above regression equation was a suitable model to describe the response of the experimental parameters (independent variables) to manufacture of spreadable modified butter.

\section{Response surface graph of SFC at $10^{\circ} \mathrm{C}$}

The model equation was applied to obtain optimal conditions of spreadable modified butter by the three-dimensional graphical methodology. The resulting three-dimensional surface plots of SFC versus two process parameters $\left(\mathrm{X}_{i}\right)$ were presented in Figs. 1, 2, and 3. As can be

Table 2. Coded levels for independent variables used in developing experimental data

\begin{tabular}{|c|c|c|c|c|c|c|c|}
\hline \multirow{2}{*}{ Variables (Content, \%) } & \multirow{2}{*}{ Coded $\mathrm{X}_{i}$} & \multicolumn{6}{|c|}{ Coded level } \\
\hline & & -2 & -1 & 0 & 1 & 2 & $\Delta \mathrm{X}$ \\
\hline Butter & $\mathrm{X}_{1}$ & 35 & 45 & 55 & 65 & 75 & 10 \\
\hline Grape seed oil & $\mathrm{X}_{2}$ & 15 & 20 & 25 & 30 & 35 & 5 \\
\hline Hydrogenated soybean oil & $\mathrm{X}_{3}$ & 0 & 1 & 2 & 3 & 4 & 1 \\
\hline
\end{tabular}


Table 3. Central composite design for the optimization of the manufacturing of process butter

\begin{tabular}{|c|c|c|c|c|c|c|c|c|c|c|c|}
\hline \multirow{2}{*}{$\begin{array}{l}\text { Run } \\
\text { No. }\end{array}$} & \multicolumn{3}{|c|}{ Coded variable } & \multicolumn{7}{|c|}{ Process variable } & \multirow{2}{*}{$\begin{array}{c}10^{\circ} \mathrm{C} \\
\mathrm{SFC}(\%)\end{array}$} \\
\hline & $\mathrm{X}_{1}{ }^{1)}$ & $\mathrm{X}_{2}{ }^{1)}$ & $\mathrm{X}_{3}{ }^{1)}$ & $\mathrm{X}_{1}$ & $\mathrm{X}_{2}$ & $X_{3}$ & But. & Oil. & Hyd. & Wat. $^{2)}$ & \\
\hline 1 & -1 & -1 & -1 & 45 & 20 & 1 & 45 & 20 & 1 & 34 & 37.27 \\
\hline 2 & 1 & -1 & -1 & 65 & 20 & 1 & 65 & 20 & 1 & 14 & 40.84 \\
\hline 3 & -1 & 1 & -1 & 45 & 30 & 1 & 45 & 30 & 1 & 24 & 32.37 \\
\hline 4 & 1 & 1 & -1 & 65 & 30 & 1 & 65 & 30 & 1 & 4 & 36.58 \\
\hline 5 & -1 & -1 & 1 & 45 & 20 & 3 & 45 & 20 & 3 & 32 & 38.91 \\
\hline 6 & 1 & -1 & 1 & 65 & 20 & 3 & 65 & 20 & 3 & 12 & 42.02 \\
\hline 7 & -1 & 1 & 1 & 45 & 30 & 3 & 45 & 30 & 3 & 22 & 33.92 \\
\hline 8 & 1 & 1 & 1 & 65 & 30 & 3 & 65 & 30 & 3 & 2 & 37.73 \\
\hline 9 & -1 & -1 & -1 & 45 & 20 & 1 & 45 & 20 & 1 & 34 & 37.27 \\
\hline 10 & 1 & -1 & -1 & 65 & 20 & 1 & 65 & 20 & 1 & 14 & 40.84 \\
\hline 11 & -1 & 1 & -1 & 45 & 30 & 1 & 45 & 30 & 1 & 24 & 32.37 \\
\hline 12 & 1 & 1 & -1 & 65 & 30 & 1 & 65 & 30 & 1 & 4 & 36.58 \\
\hline 13 & -1 & -1 & 1 & 45 & 20 & 3 & 45 & 20 & 3 & 32 & 38.91 \\
\hline 14 & 1 & -1 & 1 & 65 & 20 & 3 & 65 & 20 & 3 & 12 & 42.02 \\
\hline 15 & -1 & 1 & 1 & 45 & 30 & 3 & 45 & 30 & 3 & 22 & 33.92 \\
\hline 16 & 1 & 1 & 1 & 65 & 30 & 3 & 65 & 30 & 3 & 2 & 32.73 \\
\hline 17 & -2 & 0 & 0 & 35 & 25 & 2 & 35 & 25 & 2 & 38 & 32.69 \\
\hline 18 & 2 & 0 & 0 & 75 & 25 & 2 & 75 & 25 & 2 & 0 & 40.50 \\
\hline 19 & 0 & -2 & 0 & 55 & 15 & 2 & 55 & 15 & 2 & 28 & 42.76 \\
\hline 20 & 0 & 2 & 0 & 55 & 35 & 2 & 55 & 35 & 2 & 8 & 33.47 \\
\hline 21 & 0 & 0 & -2 & 55 & 25 & 0 & 55 & 25 & 0 & 20 & 36.16 \\
\hline 22 & 0 & 0 & 2 & 55 & 25 & 4 & 55 & 25 & 4 & 16 & 38.86 \\
\hline 23 & 0 & 0 & 0 & 55 & 25 & 0 & 55 & 25 & 0 & 20 & 36.16 \\
\hline
\end{tabular}

But., Butter; Oil., Grape seed oil; Hyd., Hydrogenated soybean oil; Wat., Water

${ }^{1)} \mathrm{X}_{1}, \mathrm{X}_{2}$ and $\mathrm{X}_{3}$ were the content of butter (\%), grape seed oil (\%) and hydrogenated soybean oil (\%), respectively.

${ }^{2)}$ Water $(\%)=100-($ Butter $(\%)+$ grape seed oil $(\%)+$ hydrogenated soybean oil $(\%))$

Table 4. Values of regression coefficients calculated for the manufacturing of process butter

\begin{tabular}{lcccc}
\hline \hline $\begin{array}{c}\text { Independent } \\
\text { variable }\end{array}$ & $\begin{array}{c}\text { Co- } \\
\text { efficient }\end{array}$ & $\begin{array}{c}\text { Standard } \\
\text { error }\end{array}$ & t-value & $\begin{array}{c}\text { Significance } \\
\text { level }(p)\end{array}$ \\
\hline Constant & 39.18 & 30.56 & 1.28 & 0.22 \\
$\mathrm{X}_{1}{ }^{1)}$ & 0.29 & 0.62 & 0.47 & 0.65 \\
$\mathrm{X}_{2}{ }^{1)}$ & -1.04 & 1.14 & -0.91 & 0.38 \\
$\mathrm{X}_{3}{ }^{1)}$ & 3.52 & 2.89 & 1.22 & 0.24 \\
$\mathrm{X}_{1}{ }^{2}$ & 0.00 & 0.01 & 0.06 & 0.95 \\
$\mathrm{X}_{1} \mathrm{X}_{2}$ & 0.00 & 0.01 & -0.52 & 0.61 \\
$\mathrm{X}_{2}{ }^{2}$ & 0.02 & 0.02 & 0.76 & 0.46 \\
$\mathrm{X}_{1} \mathrm{X}_{3}$ & -0.04 & 0.03 & -1.51 & 0.05 \\
$\mathrm{X}_{2} \mathrm{X}_{3}$ & -0.07 & 0.06 & -1.18 & 0.26 \\
$\mathrm{X}_{3}{ }^{2}$ & 0.23 & 0.51 & 0.45 & 0.66 \\
\hline $\mathrm{R}^{2}$ & & & & 0.90 \\
$\mathrm{~F}$ & & & & 61.11 \\
Probability of $\mathrm{F}$ & & & & $<0.001$ \\
\hline
\end{tabular}

${ }^{1)} \mathrm{X}_{1}, \mathrm{X}_{2}$ and $\mathrm{X}_{3}$ were the content of butter (\%), grape seed oil (\%) and hydrogenated soybean oil (\%), respectively.

seen in the surface generated by the model (Fig. 1), only content of butter $\left(\mathrm{X}_{1}\right)$ significantly affected SFC, with a positive coefficient for the linear term. According to the surface generated by the model (Fig. 3), SFC (Y, \%)

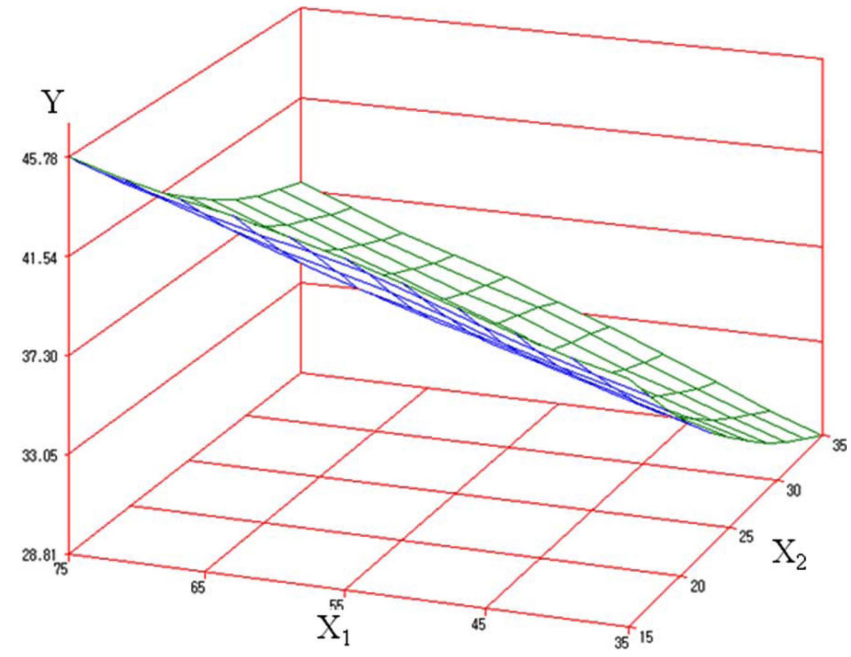

Fig. 1. Response surface for the effect of the content of butter and grape seed oil on SFC of manufacturing of spreadable modified butter. $X_{1}$, The content of butter (\%); $X_{2}$, The content of grape seed oil (\%); $Y_{1}$, SFC (\%).

showed an inverted-U shape relationship with the content of butter $\left(\mathrm{X}_{1}\right)$ and hydrogenated soybean oil $\left(\mathrm{X}_{3}\right)$. As the content increased SFC increased until reaching a certain content, at which point it leveled off (maximum is increased) 


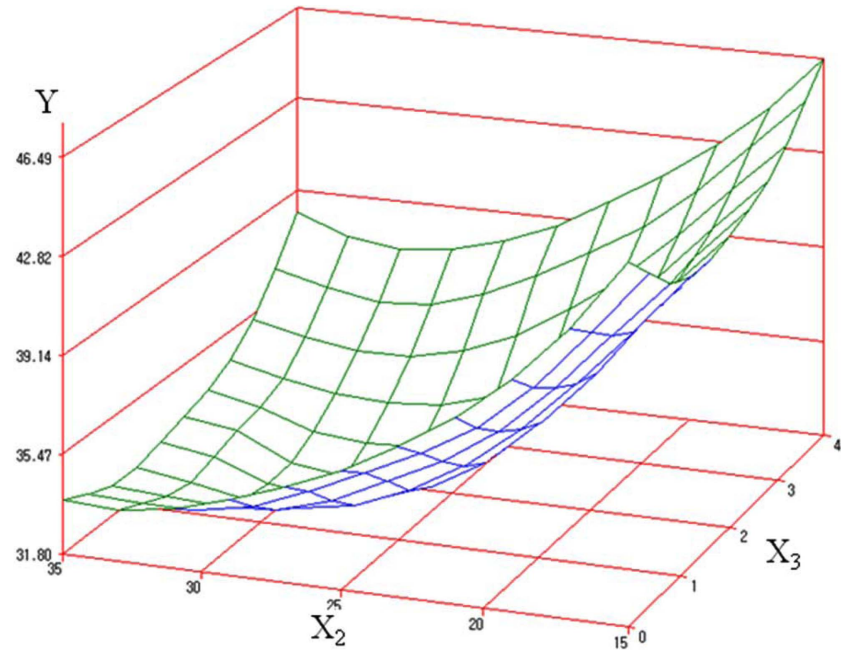

Fig. 2. Response surface for the effect of the content of butter and hydrogenated soybean oil on SFC of manufacturing of spreadable modified butter. $\mathrm{X}_{2}$, The content of grape seed oil (\%), $\mathrm{X}_{3}$, The content of hydrogenated soybean oil (\%), $\mathrm{Y}_{1}, \mathrm{SFC}(\%)$.

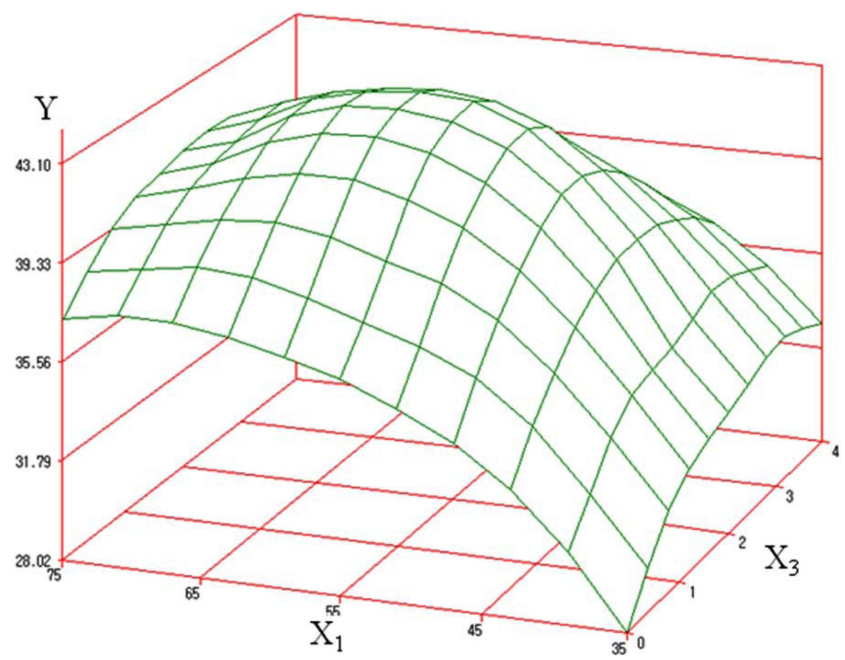

Fig. 3. Response surface for the effect of the content of grape seed oil and hydrogenated soybean oil on SFC of manufacturing of spreadable modified butter. $X_{1}$, The content of butter $(\%), \mathrm{X}_{3}$, The content of hydrogenated soybean oil (\%), $\mathrm{Y}_{1}, \mathrm{SFC}(\%)$.

and decreased downward to low SFC values. Thus, it was confirmed that the content of butter $\left(\mathrm{X}_{1}\right)$ and hydrogenated soybean oil $\left(\mathrm{X}_{3}\right)$ were believed to be the major factors affect the SFC among the variables studied. The content of grape seed oil was shown to have little effect on the SFC of spreadable modified butter.

\section{Canonical analysis}

Finally, the $\mathrm{SFC}$ at $10^{\circ} \mathrm{C}$ of spreadable modified butter was determined at the optimum conditions calculated from the canonical analysis. As the stationary point was
Table 5. Ridge of maximum response from coded radius 0.1 for optimal condition of response surface

\begin{tabular}{cccc}
\hline \hline Variable & $\begin{array}{c}\text { Coded factor } \\
\text { value }\end{array}$ & $\begin{array}{c}\text { Uncoded factor } \\
\text { value }\end{array}$ & Optimal value \\
\hline $\mathrm{X}_{1}{ }^{1)}$ & 0.37750 & 55.18056 & 45.24806 \\
$\mathrm{X}^{1}{ }^{1)}$ & 2.11843 & 40.74308 & 33.40933 \\
$\mathrm{X}_{3}{ }^{1)}$ & 1.31038 & 4.07636 & 3.342615 \\
\hline
\end{tabular}

${ }^{1)} \mathrm{X}_{1}, \mathrm{X}_{2}$ and $\mathrm{X}_{3}$ were the content of butter (\%), grape seed oil (\%) and hydrogenated soybean oil (\%), respectively.

the maximal one, the critical value reflected optimal conditions for the SFC at $10^{\circ} \mathrm{C}$ of the butter.

The critical value was shown in Table 5. The optimal conditions for the manufacturing of spreadable modified butter were determined to be the content of butter of $55.18 \%$, the content of grape seed oil of $40.78 \%$ and the content of hydrogenated soybean oil of $4.08 \%$. From these optimum compositions, $30.20 \%$ of $\mathrm{SFC}$ at $10^{\circ} \mathrm{C}$ was obtained. The predicted response value for SFC at $10^{\circ} \mathrm{C}$ was $30.20 \%$, comparable to the actual experimental $\mathrm{SFC}$ value as $29.85 \%$. Therefore, this study showed that the SFC value at $10^{\circ} \mathrm{C}$ could be a suitable indicator for the manufacturing spreadable modified butter to predict important attributes such as mouth feel, hardness and spreadability.

\section{The rheological properties on spreadable modified} butter: Hardness measurement

Finally hardness and spreadability in reference butter (80\% milk fat) and spreadable modified butter produced under the optimal conditions was measured by Texture analysis system TA-plus. The mean of hardness in spreadable modified butter was $31.80 \mathrm{~N}$ as compared to $69.92 \mathrm{~N}$ in reference butter. The judgment criteria were; $0-30 \mathrm{~N}$ was so smooth, 31-60 N was good, above $60 \mathrm{~N}$ was not so smooth. The results indicated that the spreadable modified butter was a significantly $(p<0.05)$ better than reference butter. This difference may be due to the contents of solid fat by butter and hydrogenated soybean oil.

\section{Sensory evaluation: Spreadability}

The reference butter ( $80 \%$ milk fat) and spreadable modified butter manufacturing under the optimal conditions were compared with spreadability test. The spreadability scores of reference sample and spreadable modified butter under optimal conditions were 4.5 and 5.6, respectively. The judgment criteria were; 0-3 point was not so good, 3-5 point was gsolid fat contentood, 5-7 point was very good. The spreadability scores result from 
two samples were found a significant difference. This difference may be due to the contents of solid fat by butter and hydrogenated soybean oil.

\section{References}

1. Acosta, O. F. V. and Cubero E. (2008) Optimisation of low calorie mixed fruit jelly by response surface methodology. Food Qual. Prefer. 19, 79-85.

2. Bourne, M. C. (1982) Food texture and viscosity : Concept and measurement. New York: Academic Press.

3. Damasio, M. H., Costell, E. and Duran, L. (1999) Optimising acceptability of low-sugar strawberry gels segmenting consumers by internal preference mapping. J. Sci. Food Agric. 79, 626-632.

4. DeMan, J. M. and Wood, F. W. (1958) Hardness of butter. Influence of season and manufacturing method. J. Dairy Sci. 41, 360-368.

5. DeMan, J. M. and Beers, A. M. (1987) Review : Fat crystal networks : Structure and rheological properties. J. Texture Stud. 18, 303-318.

6. Frede, E. and Precht, K. H. (1988) Streichfihigkeit und Schnittfestigkeit vakuumbehandelter Butter. Dt. Molkerei Ztg. 109, 313-317.

7. Gacula, M. (1993) Design and analysis of sensory optimization. Food and Nutrition Press, Trumbull, CT.

8. Gan, H. E., Karim, R., Muhammad, S. K. S., Baker, J. A., Hashim, D. M. and Rahman, R. (2006) Optimization of the basic formulation of a traditional baked cassava cake using response surface methodology. Lebenson. Wiss. Technol. 40, 611-618

9. Granato, D., Castro, I. A., Ellendersen, L. S. N. and Masson,
M. L. (2010a) Physical stability assessment and sensory optimization of a dairy-free emulsion using response surface methology. J. Food Sci. 75, 149-155

10. Granato, D., Ribeiro, J. C. B., Castro, I. A. and Masson, M. L. (2010b) Sensory evaluation and physicochemical optimization of soy-based desserts using response surface methology. Food Chem. 121, 899-906.

11. Kawanari, M., Hamann, D. D., Swartzel, K. R. and Hansen, A. P. (1981) Rheological and texture studies of butter. J. Texture Stud. 12, 483-505.

12. Kaylegian, K. E. and Lindsay, R. C. (1992) Performance of selected milk fat fractions in cold-spread able butter. J. Dairy Sci. 75, 3307-3317.

13. Mulder, H. and Walstra, P. (1974) The milk fat globule. Wageningen : Centre for Agricultural Publishing and Documentation. pp. 33-55.

14. Narine, S. S. and Marangoni, A. G. (1999a) Microscopic and rheological studies of fat crystal networks. J. Cryst. Growth 198, 199, 1315-1319.

15. Narine, S. S. and Marangoni, A. G. (1999b) Relating structure of fat crystal networks to mechanical properties : a review. Food Res. Int. 32, 227-248.

16. SAS (2003) SAS/STAT software for PC. Release 9.1, SAS Institute, Inc., Cary, NC, USA.

17. Shukla, A., Bhasker, A. R., Rizvi, S. S. H. and Mulvaney, S. J. (1994) Physicochemical and rheological properties of butter made from supercritically fractionated milk fat. J. Dairy Sci. 77, 45-54.

18. Singh, A. P., McClements, D. J. and Marangoni, A. G. (2004) Solid fat content determination by ultrasonic velocimetry. Food Res. Int. 37, 545-555.

(Received 2012.7.24/Revised 2012.12.7/Accepted 2012.12.13) 